\title{
Efficient Production of Hydrogen from Decomposition of Formic Acid over Zeolite Incorporated Gold Nanoparticles
}

\author{
Gallas-Hulin, Agata; Mielby, Jerrik Jørgen; Kegnæs, Søren
}

Published in:

ChemistrySelect

Link to article, DOI:

10.1002/slct.201600831

Publication date:

2016

Document Version

Peer reviewed version

Link back to DTU Orbit

Citation (APA):

Gallas-Hulin, A., Mielby, J. J., \& Kegnæs, S. (2016). Efficient Production of Hydrogen from Decomposition of Formic Acid over Zeolite Incorporated Gold Nanoparticles. ChemistrySelect, 1(13), 3942-3945.

https://doi.org/10.1002/slct.201600831

\section{General rights}

Copyright and moral rights for the publications made accessible in the public portal are retained by the authors and/or other copyright owners and it is a condition of accessing publications that users recognise and abide by the legal requirements associated with these rights.

- Users may download and print one copy of any publication from the public portal for the purpose of private study or research.

- You may not further distribute the material or use it for any profit-making activity or commercial gain

- You may freely distribute the URL identifying the publication in the public portal

If you believe that this document breaches copyright please contact us providing details, and we will remove access to the work immediately and investigate your claim. 


\title{
Efficient Production of Hydrogen from Decomposition of Formic Acid over Zeolite Incorporated Gold Nanoparticles
}

\author{
Agata Gallas-Hulin, ${ }^{[a]}$ Dr. Jerrik Mielby, ${ }^{[a]}$ Prof. Søren Kegnæs ${ }^{\star[a]}$
}

\begin{abstract}
Formic acid has a great potential as a safe and convenient source of hydrogen for sustainable chemical synthesis and renewable energy storage. Here, we report a heterogeneous gold nanoparticles catalyst for efficient production of hydrogen from vapor phase decomposition of formic acid using zeolite incorporated gold nanoparticles. The catalyst is prepared by pressure assisted impregnation and reduction (PAIR), which results in a uniform distribution of small gold nanoparticles that are incorporated into zeolite silicalite-1 crystals. Consequently, the incorporated nanoparticles exhibit increased sintering stability. Based on these results, we believe that incorporation of metal nanoparticles in zeolites may find use as highly active and selective heterogeneous catalysts for the production of hydrogen in future renewable energy applications.
\end{abstract}

Hydrogen produced from renewable resources holds great promise for the sustainable production of chemicals and clean energy. Unfortunately, the physical properties of hydrogen gas make transportation, handling and refueling difficult. Formic acid $(\mathrm{HCOOH})$ has recently attracted considerable attention due to its potential as a hydrogen storage material and as a way to utilize $\mathrm{CO}_{2}$ [1]. Since formic acid can be synthesized by hydrogenation of $\mathrm{CO}_{2}$, a possible carbon-neutral storage-and-release cycle can be envisioned, although this requires that a large amount of renewable hydrogen is readily available. Alternatively, formic acid may be produced from biomass, for instance by the catalytic oxidation of polysaccharides [2,3,4], see Figure 1.

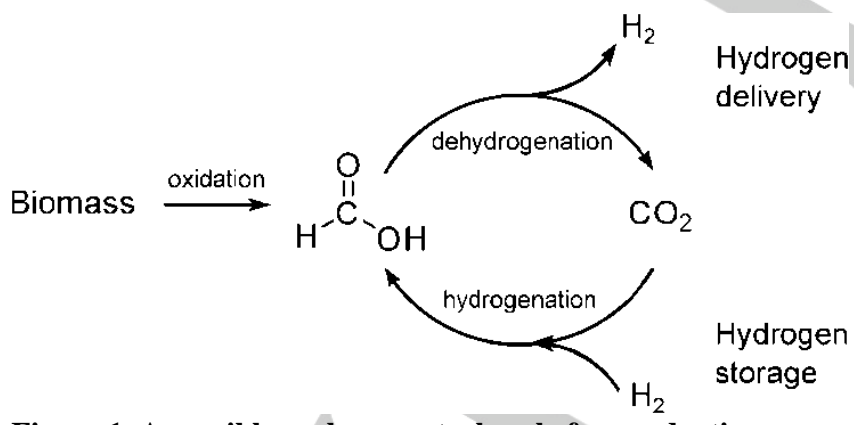

Figure 1. A possible carbon-neutral cycle for production, storage and delivery of renewable hydrogen.

The history of formic acid activation dates back to the pioneering work of Sabatier [5], who showed that its decomposition might occur via dehydrogenation (1) or

[a] A. Gallas-Hulin, J. Mielby, S. Kegnæs Department of Chemistry

Technical University of Denmark

2800 Kgs. Lyngby

E-mail: skk@kemi.dtu.dk

Supporting information for this article is given via a link at the end of the document. dehydration (2). The two reactions pathways are linked by the well-known water-gas shift reaction (WGS), see Figure 2.

Figure 2. Possible pathways for formic acid decomposition: dehydrogenation (1) and dehydration (2).

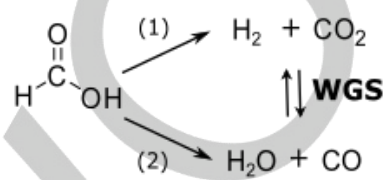

The first reaction is slightly exothermic, while the second is slightly endothermic. In general, the selective formation of $\mathrm{H}_{2}$ is favored at low reaction temperatures [6]

Recently, several noble metals have attracted attention as potential catalysts for the decomposition of formic acid, including $\mathrm{Ru}, \mathrm{Pd}$ and $\mathrm{Au}$ [7-11]. Supported Au nanoparticles have been studied as catalysts for formic acid decomposition in both liquid [12] and vapor phase [13]. In particular, Ojeda and Iglesia [14] showed that well-dispersed Au catalysts decomposed formic acid with metal-time yields higher than similar Pt catalysts under mild conditions in liquid phase. In another study, Gazsi et al. performed vapor-phase experiments to study the effect of the support and showed $\mathrm{Au} / \mathrm{SiO}_{2}$ to be the most active and selective catalyst with respect to the decomposition of formic acid and $\mathrm{H}_{2}$ formation [15]. More recently, the decomposition of formic acid has also been investigated by means of periodic density functional theory calculations. In particular, Studt et al. [16] investigated the reaction over $\mathrm{Ag}, \mathrm{Cu}, \mathrm{Pd}$ and $\mathrm{Pt}$. According to their calculations, small Au gold clusters of $0.8 \mathrm{~nm}$ in diameter are able to bind $\mathrm{CO}$ and $\mathrm{OH}$ more strongly than bulk $\mathrm{Au}$, and even be more active and selective than $\mathrm{Pt}$.

The encapsulation of metal nanoparticles in zeolites has recently attracted much attention [17]. In particular, the zeolite framework may introduce selectivity in terms of size- and shape selectivity [18][19] or prevent the encapsulated nanoparticles from sintering [20][21]. However, incorporating metal nanoparticles in zeolites often rely on complex synthetic procedures and expensive additives, which may prevent largescale production and general implementation [22].

Here, we report a simple and effective method for the incorporation of gold nanoparticles in zeolite silicalite-1. The method is based on pressure assisted impregnation and reduction. In this method, the sample is first impregnated with the gold precursor solution and then reduced in an autoclave under pressure. The pressure assisted impregnation and reduction facilitates the formation of small and well-dispersed gold nanoparticles, while conventional impregnation typically results in relatively large $(>5 \mathrm{~nm})$ and unreactive nanoparticles on silica [23]. Although, absence of strong metal-support interactions may result in severe redistribution of the impregnated metal during drying and reduction [24], simple impregnation is often preferred over more complicated preparative methods such as deposition-precipitation or co- 
precipitation [25]. The following results demonstrate that pressure assisted impregnation and reduction is a simple and effective method to prepare highly active catalysts comprised of zeolite incorporated gold nanoparticles. The detailed synthesis and characterization of all investigated catalysts by TEM, XRPD and nitrogen physisorption are given in the Supporting Information.

In order to investigate the effect of the impregnation method on the size distribution and activity of the supported gold nanoparticles, four catalysts were prepared. The first catalyst, Au/S1_PAIR, comprised 1 wt\% Au on MFI zeolite silicalite-1 (S1) was prepared by pressure assisted impregnation and reduction (PAIR) using an aqueous solution of $\mathrm{HAuCl}_{4}$ as metal precursor. After impregnation the catalyst was placed in the autoclave and subjected to 8 bar of $\mathrm{H}_{2} / \mathrm{N}_{2}$ and $150^{\circ} \mathrm{C}$ to reduce the gold precursor to nanoparticles. The second catalyst, Au/S1_IM was obtained by simple impregnation (IM) followed by drying and reduction in $\mathrm{H}_{2}$ flow at $350^{\circ} \mathrm{C}$ and atmospheric pressure. In order to investigate the sintering stability of gold nanoparticles, the two samples were additionally calcined (C) after the synthesis at $400^{\circ} \mathrm{C}$ for $3 \mathrm{~h}$ in air. These samples are named Au/S-1_PAIR_C and Au/S-1_IM_C, respectively. The detailed synthetic procedures and characterization by HRTEM, XRPD and nitrogen physisorption can be found in the Supporting Information. Table 1 shows an overview of the investigated catalysts. Additionally, the two above mentioned methods were applied to produce gold nanoparticles supported on mesoporous silica. These catalysts were used as reference samples and the information about their synthesis and characterization can be found in the Supporting Information.

Table 1. Overview of the investigated catalysts.

\begin{tabular}{cccc} 
Catalyst ${ }^{\mathrm{a}}$ & $\begin{array}{c}\text { Average diameter } \\
\text { [nm] }\end{array}$ & $\begin{array}{c}\text { Temperature of } \\
50 \% \text { conversion } \\
{\left[{ }^{\circ} \mathrm{C}\right]}\end{array}$ & $\begin{array}{c}\text { STY at } \\
120^{\circ} \mathrm{C}\end{array}$ \\
\hline Au/S-1_PAIR & $2,7 \pm 2,2$ & 113 & 113 \\
Au/S-1_IM & $4,5 \pm 3,0$ & 122 & 62 \\
Au/S-1_PAIR_C & $4,0 \pm 2,5$ & 118 & 98 \\
Au/S-1_IM_C & $8,6 \pm 3,6$ & 131 & 45
\end{tabular}

[a] All catalysts were impregnated with an amount of $\mathrm{HAuCl}_{4}(\mathrm{aq})$ corresponding to $1 w t \% \mathrm{Au}$. [b] As measured from approximately 200 nanoparticles by TEM. PAIR: pressure assisted impregnation and reduction, IM: impregnation, $\mathrm{C}$ : additional calcination at $300^{\circ} \mathrm{C}$ for $3 \mathrm{~h}$ in air.

All catalysts were characterized by TEM. For the Au/S1_PAIR catalyst the gold nanoparticles were almost exclusively located inside the zeolite crystals. The average diameter of the $\mathrm{Au}$ nanoparticles were $2,7 \pm 2,2 \mathrm{~nm}$. For comparison, the average diameter of the nanoparticles in Au/S-1_IM were 4,5 \pm $3,0 \mathrm{~nm}$. The TEM image of Au/S-1_IM in Figure 3 shows that two kinds of nanoparticles are present in the sample. Small nanoparticles, which are around $2 \mathrm{~nm}$ located inside the crystal, and large nanoparticles, which are $>5 \mathrm{~nm}$ in diameter and located on the external surface of the zeolite crystal. Based on the histogram of the particle size distribution presented in Figure 3 , particles which are the most abundant in samples Au/S1_PAIR and Au/S-1_IM are around 2,2 $\pm 0,6 \mathrm{~nm}$ and 1,9 $\pm 0,4$ $\mathrm{nm}$, respectively.
The TEM analysis of the calcined catalysts revealed that the Au/S-1_PAIR_C had an average particle size of $4,0 \pm 2,5 \mathrm{~nm}$, while Au/S-1_IM_C had an average particles of $8,6 \pm 3,6 \mathrm{~nm}$, see Table 1 . These results clearly show that the catalyst prepared by pressure assisted impregnated and reduction were significantly more stable towards sintering than the catalyst prepared by conventional impregnation.

All catalysts were tested in vapor phase decomposition of formic acid into $\mathrm{CO}_{2}$ and $\mathrm{H}_{2}$. In a typical experiment, formic acid vapour was passed through a fixed-bed quartz reactor by bubbling $40 \mathrm{ml} / \mathrm{min}$ of $\mathrm{Ar}$ through pure formic acid at $20^{\circ} \mathrm{C}$. The products were analyzed by an online non-dispersive infrared detector to quantify the amounts of formed $\mathrm{CO}$ and $\mathrm{CO}_{2}$. The formation of $\mathrm{H}_{2}$ was followed by MS.
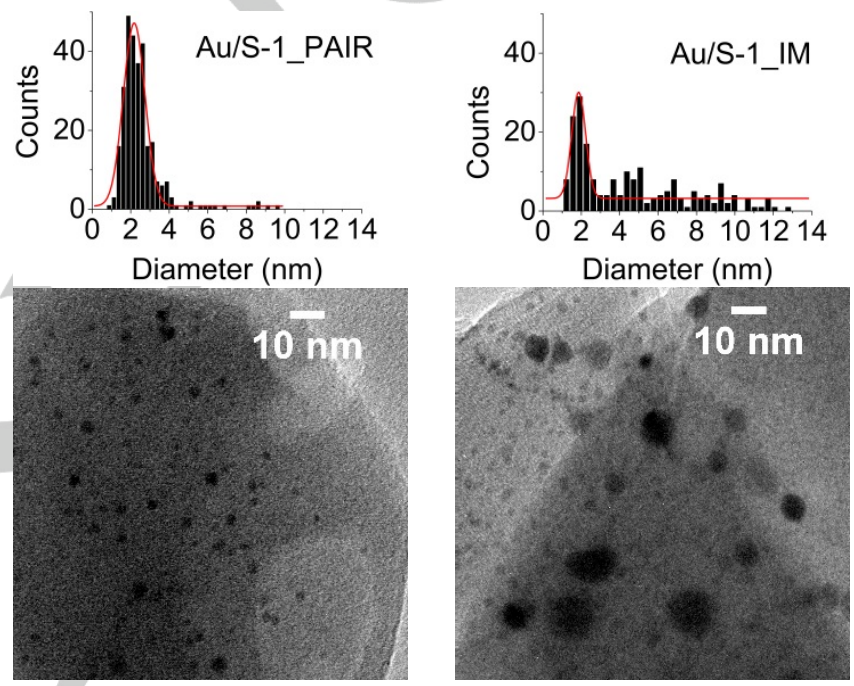

Figure 3. TEM images and nanoparticle size distribution for Au/S-1_PAIR and Au/S-1_IM catalysts.

Figure 4 shows the yield of $\mathrm{H}_{2}$ against the temperature of the reaction. The Au/S-1_PAIR catalyst exhibited the highest catalytic activity for formic acid decomposition and reached $50 \%$ conversion at $113^{\circ} \mathrm{C}$. Even after calcination at $400^{\circ} \mathrm{C}$ in air, the catalyst remained very active and reached $50 \%$ conversion at $118^{\circ} \mathrm{C}$. The Au/S-1_IM catalyst, prepared by conventional impregnation, reached $50 \%$ conversion at $122^{\circ} \mathrm{C}$, while the the calcined sample only reached $50 \%$ conversion at $131^{\circ} \mathrm{C}$, see Figure 4. The low activity is a direct consequence of the thermal deactivation caused by sintering. Selectivity towards $\mathrm{H}_{2}$ and $\mathrm{CO}_{2}$ ranged between $85-90 \%$ above $100^{\circ} \mathrm{C}$. In general, this selectivity is lower than in liquid phase (up to $100 \%$ ) [25,26], but significantly higher than previously reported for e.g. $\mathrm{Au} / \mathrm{TiO}_{2}$ in vapor phase (70\%) [27]. Comparing to the performance of other noble metals in gas phase reaction, the $50 \%$ conversion was reached for Au/S-1_PAIR catalyst at slightly higher temperatures than reported in [6] for $\mathrm{Pd} / \mathrm{C}\left(100^{\circ} \mathrm{C}\right)$, but much lower than reported in [11] for Ru supported on carbon nanofibers $\left(190^{\circ} \mathrm{C}\right)$. However, it has to be noted that the materials were tested at different conditions. 


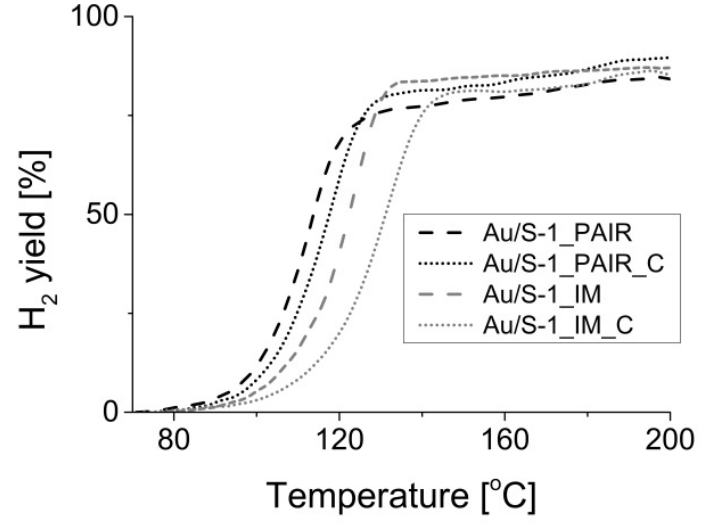

Figure 4. Yield of hydrogen as a function of temperature of the reaction temperature.

The catalyst stability tests were carried out at $120^{\circ} \mathrm{C}$ (around $50 \%$ conversion) of the Au/S-1_PAIR catalyst and Au/S-1 IM catalyst over the course of $28 \mathrm{~h}$, see Figure 5 . The catalytic tests revealed that the catalysts were stable and showed no sign of deactivation

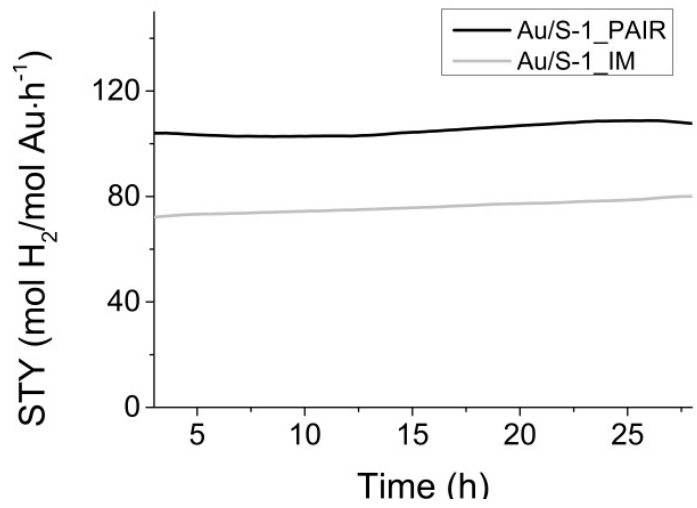

Figure 5. Catalyst stability test performed at $120^{\circ} \mathrm{C}$ for $\mathrm{Au} / \mathrm{S}$ 1_PAIR and Au/S-1_IM for $28 \mathrm{~h}$. STY is defined as $\mathrm{mol} \mathrm{H}_{2} / \mathrm{mol}$ Au hour-1.

In conclusion, we have developed a simple and effective method to incorporate gold nanoparticles into silicalite-1 zeolite crystals using pressure assisted impregnation and reduction. The prepared catalysts contain small nanoparticles with a narrow size distribution of around $2 \mathrm{~nm}$, which are readily accessible to formic acid through the inherent microporous framework. The incorporated nanoparticles were highly active for the formation of $\mathrm{H}_{2}$ by vapor phase decomposition of formic acid, even after exposure to high temperatures. We therefore expect that pressure assisted impregnation and reduction of zeolites and zeolite like materials may become a helpful tool in the development of new materials with improved catalytic properties.

Supplementary Information provides details about synthesis and characterization of discussed catalysts using TEM, XRD, and $\mathrm{N}_{2}$ physissorption as well as catalytic activity of the reference catalysts in gas phase decomposition of formic aid.

\section{Acknowledgements}

The authors gratefully acknowledge the support of the Danish Council for Independent Research, Grant No. 12-127580, the support of the Lundbeck Foundation (Lundbeckfonden), Grant No. R141-2013-13244 and the support from VILLUM FONDEN research grant (13158).

Keywords: encapsulation • formic acid $\bullet$ gold nanoparticles $•$ heterogeneous catalysis $\bullet$ zeolites

[1] S. Moret, P. J. Dyson, G. Laurenczy, Nat. Commun., 2014, 5, 4017

[2] R. Wölfel, N. Taccardi, A. Bösmann, P. Wasserscheid, Green Chem. 2011, 13, 2759

[3] N. V. Gromov, O. P. Taran, I. V. Delidovich, A. V. Pestunov, Y. A. Rodikova, D. A. Yatsenko, E. G. Zhizhina, V. N. Parmon, Catal. Today, 2016

[4] T. Flannelly, M. Lopes, L. Kupiainen, S. Dooley, J. J. Leahy, RSC Advances, 2016, 6, 5797-5804

[5] P. Sabatier, A. Maille, Compt. Rendus 1911, 152, 1212

[6] D. A. Bulushev, S. Beloshapkin, J. R.H. Ross, Catal. Today, 2010, 154

[7] D. A. Bulushev, L. G. Bulusheva, S. Beloshapkin, T. O'Connor, A. V. Okotrub, K. M. Ryan, ACS Applied Mater. Interfaces, 2015, 7, 87198726

[8] D. A. Bulushev, M. Zacharska, A. S. Lisitsyn, O. Y. Podyacheva, F. S Hage, Q. M. Ramasse, U. Bangert, L. G. Bulusheva, ACS Catalysis, 2016, 6, 3442-3451

[9] D. A. Bulushev, M. Zacharska, E. V. Shlyakhova, A. L. Chuvilin, Y. Guo, S. Beloshapkin, A. V. Okotrub, L. G. Bulusheva, ASC Catalysis, 2016, 6, 681-691

[10] L. Jia, D. A. Bulushev, J. R. H. Ross, Catal. Today, 2016, 259, 453-459

[11] M. Zacharska, O. Y. Podyacheva, L. S. Kibis, A. I. Boronin, B. V. Senkovskiy, E. Y. Gerasimov, O. P. Taran, A. B. Ayusheev, V. N. Parmon, J. J. Leahy, D. A. M. Bulushev, ChemCatChem, 2015, 7 , 2910-2917

[12] M. Yadav, T. Akita, N. Tsumori, Q. Xu, J. Mater. Chem., 2012, 22 , 12582.

[13] D. A. Bulushev, J.H.R. Ross, Catal. Today, 2011, 163, 42.

[14] M. Ojeda, E. Iglesia, Angew. Chem. 2009, 121, 4894.

[15] Gazsi, T. Bansagi, F. Solymosi, J. Phys. Chem., 2011, 60.

[16] J. Suk Yoo, F. Abild-Pedersen, J. K. Nørskov, F. Studt, ACS Catal. 2014, 4, 1226

[17] W. Grunert et al, Phys. Status Solidi B, 2013, 250, 1081.

[18] A. B. Laursen, K. T. Højholt, S. B. Simonsen, L. F. Lundegaard, S. Helveg, F. Schüth, M. Paul, J. D. Grunwaldt, S. Kegnæs, C. H. Christensen, K. Egeblad, Angew. Chem., 2010, 49, 3505.

[19] J. Mielby, J. O. Abildstrøm, F. Wang, T. Kasama, C. Weidenthaler, S Kegnæs, Angew. Chem., 2014, 53, 12513.

[20] K. Højholt, A. B. Laursen, S. Kegnæs, C. H. Christensen, Top. Catal., 2011, 54 (16) 1026.

[21] T. W. Hansen, A. T. DeLaRiva, S. R. Challa, A. K. Datya, Acc. Chem Res., 2013, 46, 1720.

[22] S. Goel, S. I. Zones, E. Iglesia, J. Am. Chem. Soc. 2014, 136, 15280.

[23] M. Haruta, Gold Bull., 2004, 37, 1.

[24] J. A.Schwarz, Chem. Rev., 1995, 95, 477.

[25] Q. Bi, X. Du, L. He, Y. Liu, Y. Cao, H. He, et al., J. Am. Chem. Soc., 2012, 134, 8926.

[26] M. Yadav, T. Akita, N. Tsumori, Q. Xu, J. Mater. Sci., 2012, 22, 12582. 
[27] D.A. Bulushev, S. Beloshapkin, J.R.H. Ross, Catal. Today., 2010, 154, 


\section{Entry for the Table of Contents}

\section{COMMUNICATION}

Pressure assisted impregnation and reduction (PAIR) is a simple and effective method to incorporate small gold nanoparticles into zeolite silicalite-1. The zeolite incorporated nanoparticles show good catalytic activity for production of $\mathrm{H}_{2}$ from vapour phase decomposition of formic acid

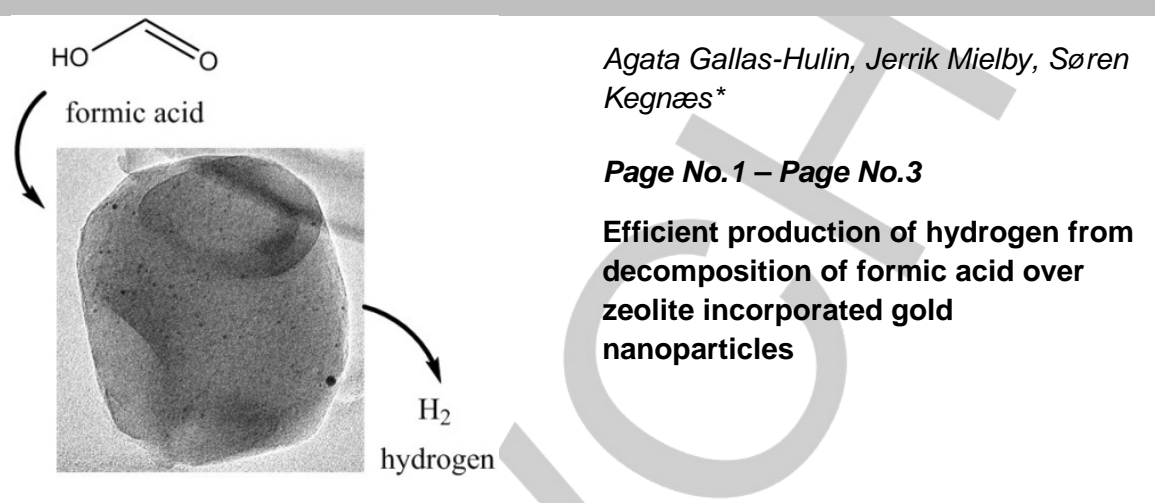

